\title{
Evaluation of the Performance of Glasphalt Concrete Mixtures for Binder Course
}

\author{
Roaa H. Latief \\ Department of Civil Engineering, Baghdad University,Baghdad, 10071, Iraq \\ E-mail: roaa.hamed@coeng.uobaghdad.edu.iq
}

\begin{abstract}
The vast and increasing quantities of waste materials produced by humans and accumulating in landfills are causing serious environmental problems around the world. Recycling is one of the most effective ways of protecting the natural environment, conserving natural resources, and achieving sustainability. Glass is one of the most widely used solid waste materials and can be readily recycled. The objective of this study is to evaluate the performance of an asphalt mixture for binder course that uses different percentages of crushed glass as an aggregate substitution. Asphalt mixtures comprising crushed glass as an aggregate are called glasphalt and have been used since the late 1960s. Two types of the mix were prepared: one with fractured aggregate only (control mix), and one with aggregates blended with recycled glass (glasphalt mix). Adding $2 \%$ of hydrated lime as an anti-stripping additive to the glasphalt mixture helps improve its resistance to moisture damage. The results indicate that the performance of the glasphalt mixture is superior in comparison to the conventional asphalt mixture. It is therefore desirable to replace the natural aggregate with crushed glass in asphalt mixtures up to $20 \%$ by weight of total aggregate with a maximal particle size of $4.75 \mathrm{~mm}$.
\end{abstract}

Keywords - glasphalt; waste glass; hydrated lime; stripping; permanent deformation.

\section{INTRODUCTION}

Waste is any material that is abandoned following primary use. Every day, various waste materials are produced by households, manufacturing processes, domestic wastewater treatment plants, industrial production, and mining. The increased quantities of such materials cause environmental pollution and therefore require high investment for spaces used as landfills [1]. Studies and surveys indicate that solid waste quantities in Iraq increased from 3.8 million tons in 1995 to 10.18 million tons in 2013, and are expected to reach up to 30.4 million tons in 2050 as a result of the increase in the Iraqi population, rising living standards, and industrial progress-all since the ending of the economic sanctions against Iraq in 2003 [2]. The most effective way in which solid waste materials can be managed is through attempting to reuse them as raw materials or modifiers in many fields. Approximately $50 \%$ of all domestic waste and $70 \%$ of industrial and construction waste materials must be recycled and reused by 2020 [3]. In the last decade, different recycled waste materials have been taken into consideration by many researchers to develop the performance of asphalt mixtures and reduce waste disposal problems. Glass is one waste type that has been widely utilised in daily life. Waste glass is suitable for a variety of applications, such as embankments, flexible base, asphalt anti-stripping agents, asphalt-stabilized base, excavation and backfill for structures, retaining walls, pipe underdrains, and open-graded base courses [4]. This paper examines the effects on the performance of asphalt mixture in employing recycled crushed glass as an alternative to aggregate.

Glass is inorganic and non-metallic; thus, it can be neither incinerated nor decomposed and can be recycled many times [5]. Annually, approximately 10 million tons of waste glass is generated worldwide. Moreover, glass comprises around 3-5 wt $\%$ of household waste [6].

Waste glass commonly referred to as cullet, is crushed and used in asphalt mixture as alternative aggregate. This mixture, known as 'glasphalt,' was first applied in the United States and Canada in 1960 [7]. Crushed waste glass in asphalt mixture must pass $100 \%$ sieve $3 / 8$, and be no more than $7 \%$ passing sieve No. 200, as well as used crushed glass with a percentage of up to $15 \%$ and added anti-stripping agents [8], [9].

Using a large size of glass waste pieces, more than 2.36 $\mathrm{mm}$, will reduce the performance of the pavement, causing raveling and stripping problems to appear [10]. A glasphalt mixture is used in the pavement layers below the upper layer to limit the stripping and surface raveling problems. It is not recommended for the upper layer [7]. One of the disadvantages of the glasphalt mixture is the stripping problem because the smoothness of the glass surface and the high silica content made them act like hydrophilic materials 
[11]. Therefore, various types of anti-stripping agents are added to glasphalt mixtures, and the most successful agent is hydrated lime, as recommended by previous studies [8].

Many studies have been performed about the feasibility and environmental suitability of using glasphalt and their resulting performance properties in the asphalt mixture. Reference [12] investigated the performance of an asphalt mix for surface layer by replacing some of the fine aggregates with a crushed glass of various percentages: $5 \%$, $10 \%, 15 \%$, and $20 \%$. They concluded that the optimal percent of glass that satisfies the performance properties of the mixture is $10 \%$. Reference [13] stated that the dynamic properties of the glasphalt mix are improved in comparison with the ordinary mix.

The results of [14] showed that the glasphalt mix with $15 \%$ of glass content for the upper layer could outperform the conventional mix in terms of rutting resistance and durability performance but failed at fatigue performance, which was attributed to the fact that the glasphalt was stiffer than the conventional mixture at typical conditions. On the other hand, reference [15] evaluated the rutting performance for the base course by adding waste crushed glass in quantities up to $50 \%$, and the results reveal that adding up to $30 \%$ of glass does not affect rutting performance.

This study aimed to evaluate the feasibility of substituting some of the natural aggregates with crushed glass for the hot asphalt mixture of binder course. To this aim, asphalt mixtures were made with crushed glass for different replacement percentages of 5\%,10\%, 15\%, 20\%, and $25 \%$ by the weight of total aggregates then tested to assess the performance of hot asphalt mixtures, which are suitable for binder course.

\section{MATERIALS AND METHODS}

\section{A. Material Selection}

The raw materials used in this work are as follows:

1) Aggregate: The natural aggregate used in this work was obtained from Al-Nibaie quarry, located in BaghdadIraq, since this is most widely used in local asphaltic mixtures. The aggregates were sieved and recombined in the proper proportions to meet the binder course gradation. As stipulated by the Iraqi state commission of roads and bridges specification [16], as shown in Table 1 and plotted in Fig. 1, a maximum size of $19 \mathrm{~mm}$ (3/4" in) was used. The selected aggregate gradation fell in the middle of the limits, and the properties of coarse and fine aggregate are summarized in Table 2.

TABLE I

Gradation Of AgGREgAte FOR AsPhAlt Binder COURSE

\begin{tabular}{|c|c|c|}
\hline \multirow{2}{*}{ Sieve Size } & \multicolumn{2}{|c|}{ \% Passing by Weight } \\
\cline { 2 - 3 } & Selected Grade & $\begin{array}{c}\text { Specification Limits } \\
{[\mathbf{1 6}]}\end{array}$ \\
\hline $1 "(25 \mathrm{~mm})$ & 100 & 100 \\
\hline $3 / 4^{\prime \prime}(19 \mathrm{~mm})$ & 95 & $90-100$ \\
\hline $1 / 2 "(12.5 \mathrm{~mm})$ & 80 & $70-90$ \\
\hline $3 / 8^{\prime \prime}(9.5 \mathrm{~mm})$ & 69 & $56-80$ \\
\hline No.4 $(4.75 \mathrm{~mm})$ & 50 & $35-65$ \\
\hline No.8 $(2.36 \mathrm{~mm})$ & 35 & $23-49$ \\
\hline No.50 $(0.3 \mathrm{~mm})$ & 13 & $5-19$ \\
\hline No.200 $(0.075 \mathrm{~mm})$ & 6 & $3-9$ \\
\hline
\end{tabular}

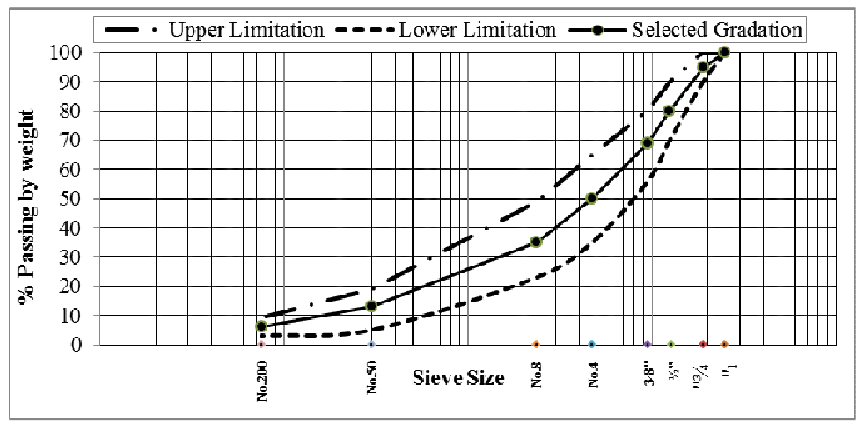

Fig. 1 Aggregate gradation curve for asphalt binder course

TABLE II

PROPERTIES OF Fine AND COARSE AgGREgates

\begin{tabular}{|l|l|c|c|}
\hline No. & \multicolumn{1}{|c|}{ Test } & \multirow{2}{*}{ Results } & $\begin{array}{c}\text { Specification } \\
\text { Limits [16] }\end{array}$ \\
\cline { 1 - 2 } Coarse Aggregate & 2.672 & - \\
\hline 1 & $\begin{array}{l}\text { Unit Weight (Apparent), } \\
\text { gm/cm }\end{array}$ & 2.65 & - \\
\hline 2 & $\begin{array}{l}\text { Unit Weight (Bulk), } \\
\text { gm/cm }\end{array}$ & 0.23 & - \\
\hline 3 & Water Absorption, $\%$ & 94 & 90 Min \\
\hline 4 & Fractured Pieces, $\%$ & 4 & $10 \mathrm{Max}$ \\
\hline 5 & Elongated and Flat 1:5,\% & 19.4 & $30 \mathrm{Max}$ \\
\hline 6 & Los Angeles Abrasion, $\%$ & 4.22 & $18 \mathrm{Max}$ \\
\hline 7 & Soundness, \% & 0.83 & $3 \mathrm{Max}$ \\
\hline 8 & $\begin{array}{l}\text { Clay Lumps and Friable } \\
\text { Particles, } \%\end{array}$ & & \multicolumn{2}{|c}{} \\
\hline
\end{tabular}

\begin{tabular}{|l|l|c|c|}
\hline \multicolumn{4}{|l|}{ Fine Aggregate } \\
\hline 1 & $\begin{array}{l}\text { Unit Weight (Apparent), } \\
\mathrm{gm} / \mathrm{cm}^{3}\end{array}$ & 2.681 & - \\
\hline 2 & $\begin{array}{l}\text { Unit Weight (Bulk), } \\
\mathrm{gm} / \mathrm{cm}^{3}\end{array}$ & 2.62 & - \\
\hline 3 & Water Absorption, $\%$ & 0.37 & - \\
\hline 4 & Angularity, $\%$ & 58.42 & - \\
\hline 5 & Sand Equivalent, $\%$ & 72.13 & $45 \mathrm{Min}$. \\
\hline 6 & $\begin{array}{l}\text { Clay Lumps and Friable } \\
\text { Particles, } \%\end{array}$ & 2.24 & $3 \mathrm{Max}$ \\
\hline
\end{tabular}

2) Asphalt Cement: Asphalt cement with a $40 / 50$ penetration grade was used in this study, and was obtained from the Al- Dora oil refinery in Baghdad-Iraq. Table 3 presents the properties of the asphalt cement.

TABLE III

PROPERTIES OF ASPHALT CEMENT

\begin{tabular}{|l|c|c|}
\hline \multicolumn{1}{|c|}{ Test } & Results & $\begin{array}{c}\text { Specification } \\
\text { Limits [16] }\end{array}$ \\
\hline Penetration, $0.1 \mathrm{~mm}$ & 46 & $40-50$ \\
\hline Specific Gravity, gm $/ \mathrm{cm}^{3}$ & 1.03 & ----- \\
\hline Ductility, cm & 121 & $>100$ \\
\hline Flash Point, ${ }^{\circ} \mathrm{C}$ & 286 & $>232$ \\
\hline Fire Point, ${ }^{\circ} \mathrm{C}$ & 326 & ----- \\
\hline Softening Point, ${ }^{\circ} \mathrm{C}$ & 50 & ----- \\
\hline
\end{tabular}

3) Mineral Filler: Limestone filler in this study was brought from lime factory in Karbala, located in south-east 
of Iraq. Table 4 summarizes the physical properties of limestone filler.

TABLE IV

PROPERTIES OF LIMESTONE

\begin{tabular}{|l|c|c|}
\hline Property & Results & $\begin{array}{c}\text { Specification } \\
\text { Limits [16] }\end{array}$ \\
\hline Unit Weight, gm/cm ${ }^{3}$ & 2.74 & ---- \\
\hline Passing Sieve No.200, \% & 95 & $70-100$ \\
\hline
\end{tabular}

4) Recycled Waste Glass: Recycled glass is produced by collecting the glass from household garbage like bottles, jars, and food containers as shown in Fig. 2. Waste glass is cleaned and washed to remove labels and exotic materials, then dried and crushed to appropriate gradation mechanically by using Los Angeles machine. Crushed glass sizes used in this study for sieves No. 4, No.8, No. 50, and No. 200, and then combined with aggregate at substitution rates of $5 \%, 10 \%, 15 \%, 20 \%$, and $25 \%$ by weight of total aggregate.

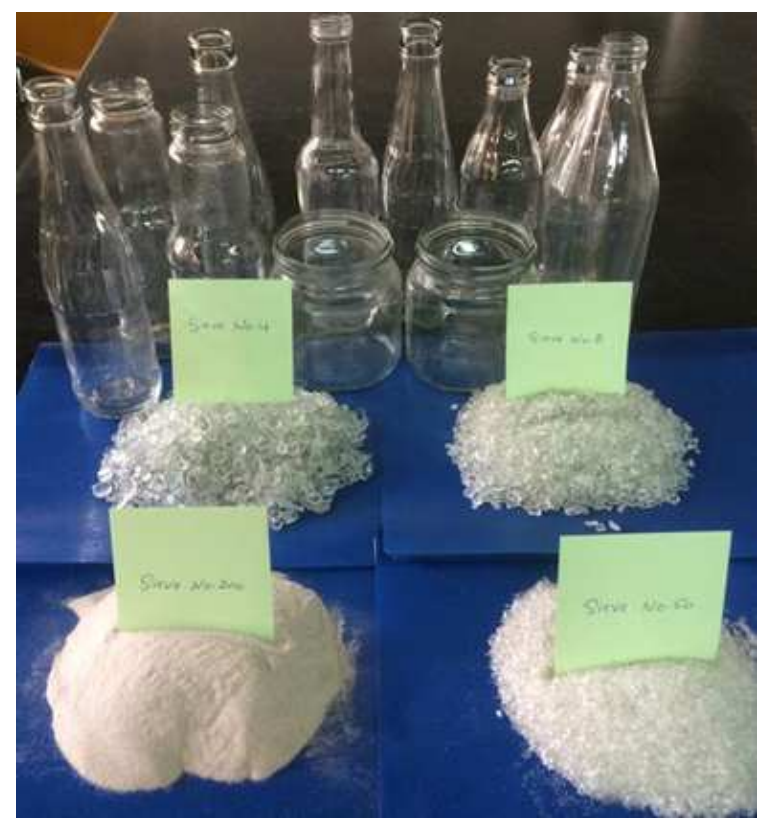

Fig. 2 Crushed waste glass

5) Anti-Stripping Agent: The addition of $2 \%$ of hydrated lime by weight of total aggregate as anti-stripping agent was used in this study to minimize potential stripping problems for glasphalt mixtures and was brought from lime factory in Karbala-Iraq. The properties of hydrated lime are listed in Table 5.

TABLE V

PROPERTIES OF HYDRATED LIME

\begin{tabular}{|c|c|}
\hline Property & Test Result \\
\hline Unit Weight, gm/ $/ \mathrm{cm}^{3}$ & 2.42 \\
\hline Passing Sieve No.200, \% & 93 \\
\hline
\end{tabular}

\section{B. Experemntal Work}

The laboratory tests were conducted to examine the performance of glasphalt mixture and to find out the suitability of using crushed waste glass as an alternative to natural aggregate in hot asphalt mixtures.
1) Marshall Test: Specimens are prepared, compacted, and tested according to the Marshall method, designated as ASTM D6927-15. The aggregate was blended for each specimen according to the binder course gradation. Then the aggregates and asphalt cement are heated for 2 hours before mixing to a temperature up to $1350 \mathrm{C}$ and $1450 \mathrm{C}$, respectively. Excess heating and pre-heating of asphalt were avoided because they cause variability in the asphalt properties. The selected amount of asphalt cement was added to the heated aggregate and mixed for at least three minutes until a uniform mixture was achieved, i.e., all aggregate and glass particles were coated with asphalt cement. In the Marshall test, standard cylindrical molds (102 $\mathrm{mm}$ in diameter and $64 \mathrm{~mm}$ in height) were heated up to 130 ${ }^{\circ} \mathrm{C}$, and the hot mixture is placed in the mold and compacted by a Marshall hammer for 75 blows on each side of the specimen. Marshall Specimens of glasphalt and control mixes are shown in Fig. 3. Marshall Stability and flow were tested using a Marshall apparatus, as illustrated in Fig. 4.

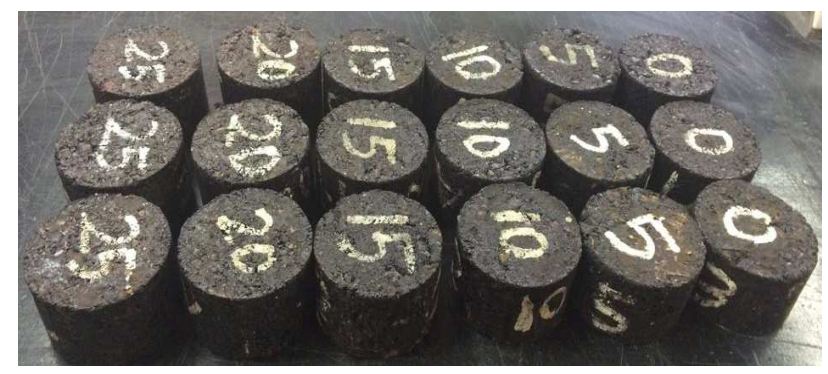

Fig. 3 Marshall specimens

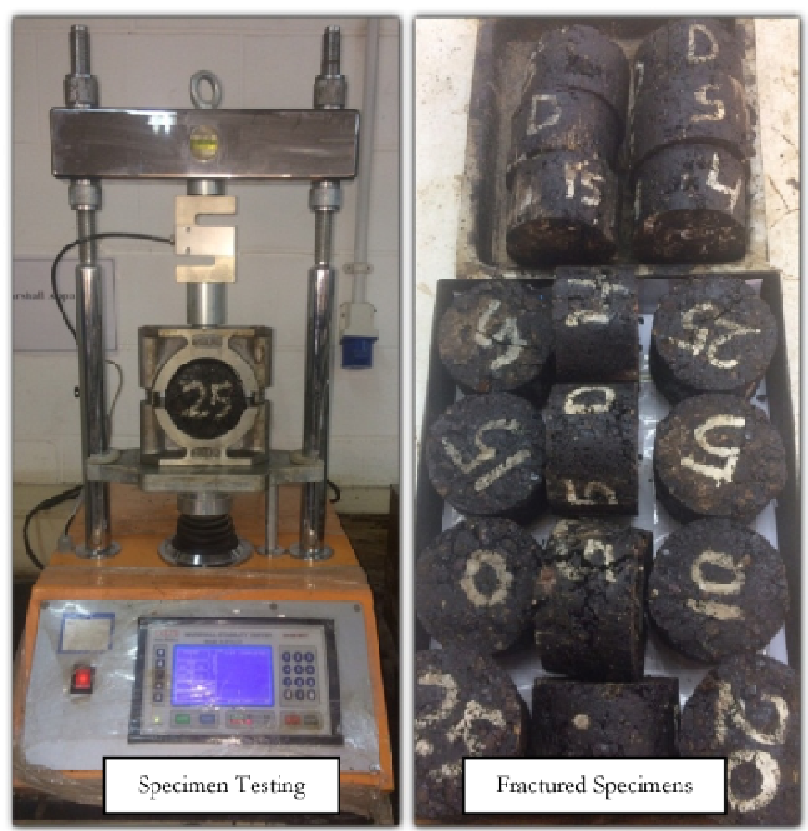

Fig. 4 Marshall Test

2) Indirect Tensile Strength Test and Temperature Susceptibility: Based on the ASTM D6931-07 specification, Marshall specimens were conditioned by immersion in water baths at three temperatures $\left(25,40\right.$, and $\left.60{ }^{\circ} \mathrm{C}\right)$ for half an hour, and ITST was conducted by loading the specimen vertical diametrically in compression with a constant rate of 
$50 \pm 5 \mathrm{~mm} /$ minute by Versa tester machine until reached the maximum load to failure, as shown in Fig. 5. The ITS can be obtained as shown below :

$$
I T S=\frac{2000 * P}{\pi H D}
$$

Where ITS is the indirect tensile strength (Kpa), $\mathrm{P}$ is the failure load $(\mathrm{N}), \mathrm{H}$ is the height of sample $(\mathrm{mm})$, and $\mathrm{D}$ is the diameter of a sample ( $\mathrm{mm}$ ).

The temperature susceptibility was obtained by applying the following equation [17]:

$$
T S=\frac{(I T S) t 1-(I T S) t 2}{t 2-t 1}
$$

in which:

$\mathrm{TS}=$ Temperature Susceptibility, $\left(\mathrm{Kpa} /{ }^{\circ} \mathrm{C}\right)$

$(\mathrm{ITS})_{\mathrm{t} 1}=$ Indirect Tensile Strength at $\mathrm{t}_{1}, \mathrm{Kpa}$

$(\text { ITS })_{\mathrm{t} 2}=$ Indirect Tensile Strength at $\mathrm{t}_{2}, \mathrm{Kpa}$

$\mathrm{t}_{1}=25^{\circ} \mathrm{C}$.

$\mathrm{t}_{2}=40^{\circ} \mathrm{C}$
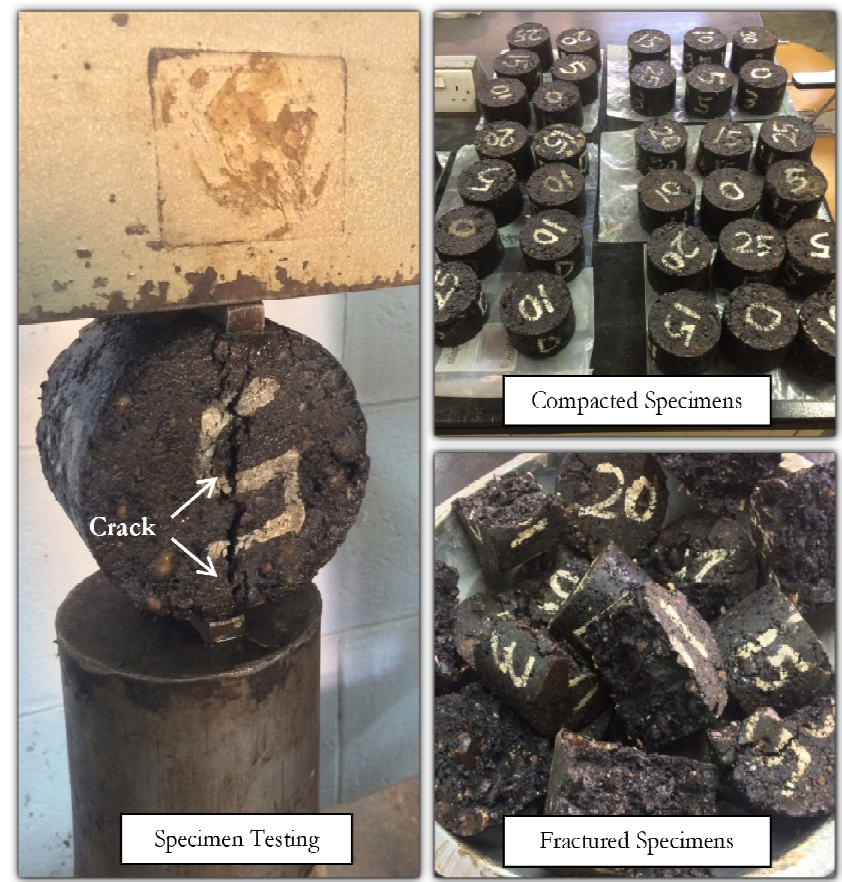

Fig. 5 Indirect tensile strength test

3) Moisture Damage Test: Accordance with ASTM D 4867M-96, tensile strength ratio was evaluated to examine the resistance of compacted mixtures against water damage. This test is recommended to indicate the loss of adhesion between asphalt and aggregate particles that is resulting from the existence of water. Briefly, the procedure of this test as follows, a group of Marshall Samples was prepared for each glass replacement percentage. The set was divided into two groups, the first group (unconditioned) was soaked in a water bath for 20 minutes at temperature $25 \pm 1{ }^{\circ} \mathrm{C}$ and the other group (conditioned) was subjected to one cycle of freezing and thawing then soaked in a water bath for one hour at temperature $25 \pm 1{ }^{\circ} \mathrm{C}$. Subsequently, the two groups tested by Versa tester machine with a loading rate of (50.8 $\mathrm{mm} /$ minute) until the peak load is achieved and the sample completely fractures, as shown in Fig. 6. Tensile strength ratio (TSR) must be at least $80 \%$. The TSR value can be obtained by applying the following equation:

$$
T S R=\frac{I T S_{2}}{I T S_{1}} * 100
$$

Where TSR is the tensile strength ratio $(\%), \mathrm{ITS}_{2}$ is the average tensile strength of conditioned group (Kpa) while ITS $_{1}$ is the average tensile strength of unconditioned group (Kpa).
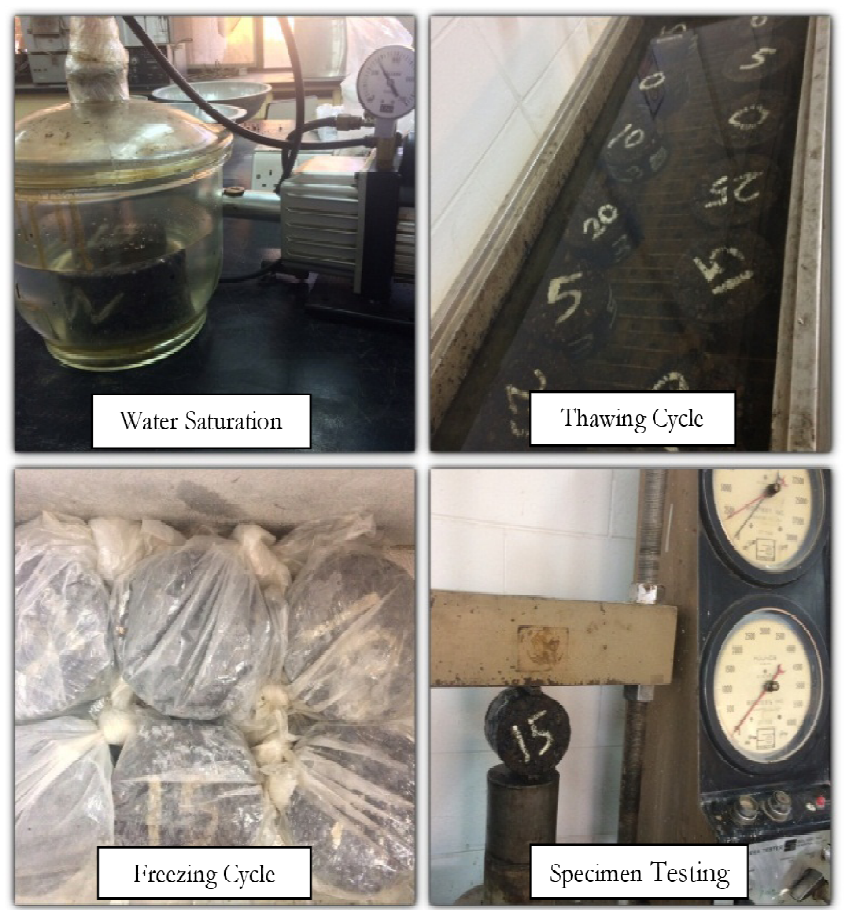

Fig. 6 Moisture damage test

4) Double Punch Shear Test: At the University of Arizona in 1973, Jimenez [18] developed double punching shear test (DPS) to measuring the tendency of binder to strip from the aggregate. Marshall Specimens were conditioned before the test by soaking in a water bath at $60^{\circ} \mathrm{C}$ for $30 \mathrm{~min}$. The DPS test was carried by centrally loading the sample which was fixed between two cylindrical steel punches $(25.4$ $\mathrm{mm}$ in diameter) on the bottom and top side of it, aligned one over the other and then loaded at a rate of $2.54 \mathrm{~cm} / \mathrm{min}$ until failure, as shown in Fig. 7. Specimens were allowed to fracture till the maximum load of failure was observe and record the reading of dial gauge. The punching strength was determined by applying the below relationship [19]:

$$
\sigma=\frac{P}{\pi\left(1.2 b h-a^{2}\right)}
$$

Where $\sigma t$ is the punching shear stress $(\mathrm{Kpa}), \mathrm{P}$ is the failure load $(\mathrm{N}), \mathrm{b}$ is the radius of specimen $(\mathrm{mm}), \mathrm{h}$ is the height of specimen $(\mathrm{mm})$ and $\mathrm{a}$ is the radius of punch $(\mathrm{mm})$. 


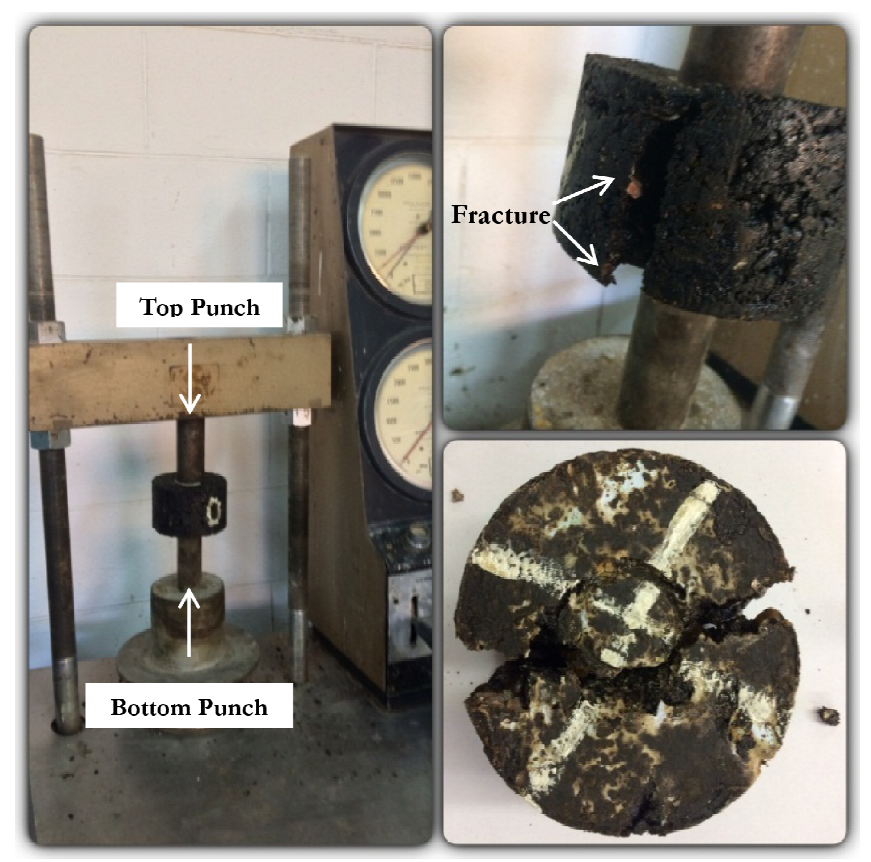

Fig. 7 Double punching shear test

5) Uniaxial Repeated Loading Test: The pneumatic repeated load system PRLS was advanced at the University of Baghdad by Albayati [20] to prediction the permanent axial deformation of the asphalt concrete mixture under repeated loading. Cylindrical specimens $(102 \mathrm{~mm}$ in diameter and $203 \mathrm{~mm}$ in height) was prepared and used for repeated loading test, as illustrated in Fig. 8. At a temperature of $600 \mathrm{C}$, a repetitive compressive loading was applied in the form of a rectangular wave with a constant loading frequency of one cycle per second. Over test duration, A heavier sine pulse of $0.1 \mathrm{sec}$ load duration and $0.9 \mathrm{sec}$ rest period is applied. Permanent strain ( $\varepsilon p)$ is computed by employing the equation below [21]:

$$
\varepsilon_{p}=\frac{P_{d} * 10^{6}}{h}
$$

Where $\boldsymbol{\varepsilon}_{\mathrm{p}}$ is the axial permanent microstrain, $\mathrm{P}_{\mathrm{d}}$ is the axial permanent and $(\mathrm{h})$ is the height of the sample.

The permanent strain $\left(\varepsilon_{\mathrm{p}}\right)$ are plotted against repetitions number $(\mathrm{N})$ for each sample to find plastic coefficients, the intercept (a) and the slope (b), these coefficients can be determined from the following equation as shown below which is originally suggested by Monismith et al.[22] and Barksdale [23]:

$$
\varepsilon_{p}=a N^{b}
$$

in which:

$\mathrm{a}=$ permanent strain at $\mathrm{N}=1$.

$b=$ rate of change in the permanent strain.

The permanent deformation parameters Alpha $(\alpha)$ and $\mathrm{Mu}$ $(\mu)$ were calculated by applying the equations as following [21]:

$$
\begin{gathered}
\alpha=1-b \\
\mu=\frac{a_{*} b}{\varepsilon_{r}}
\end{gathered}
$$

Where Alpha $(\alpha)$ is representing the rate of decrease in incremental permanent deformation as the number of repeated load applications increases and $\mathrm{Mu}(\mu)$ is indicating the constant of proportionally between resilient strain ( $\varepsilon r$ ) and permanent strain. The resilient strain $\left(\varepsilon_{\mathrm{r}}\right)$ is calculated as follows:

$$
\varepsilon_{r}=\frac{r d * 10^{6}}{h}
$$

Where $\left(r_{d}\right)$ is the axial resilient deflection and (h) is the height of sample.

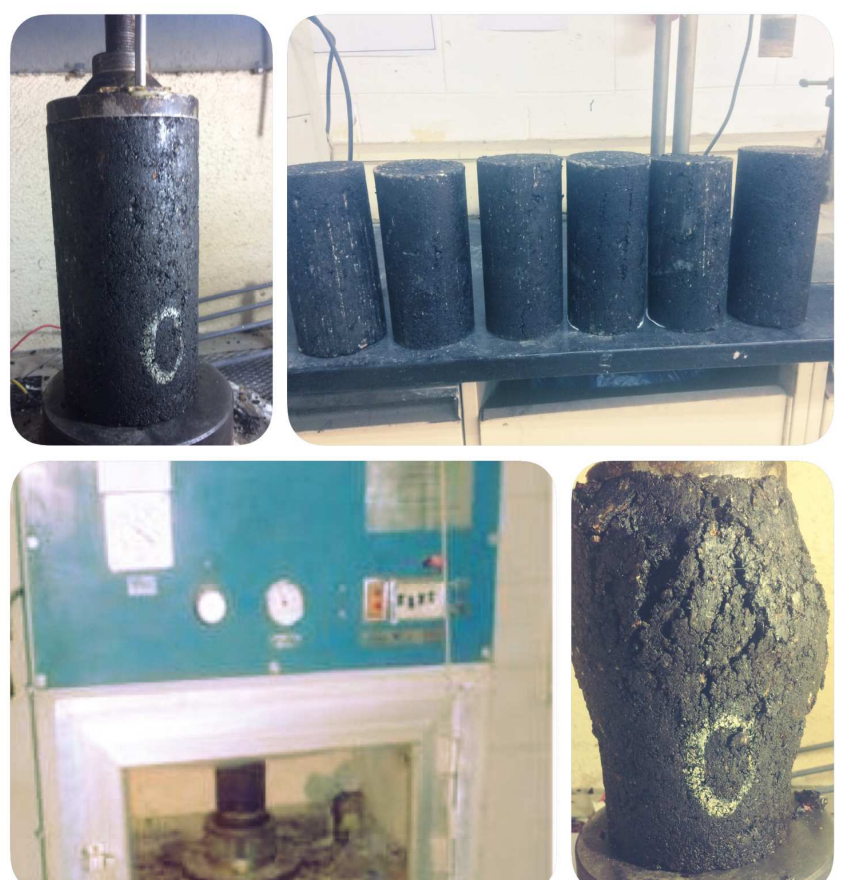

Fig. 8 Uniaxial repeated loading test

\section{RESULTS AND DISCUSSION}

Two asphalt mixtures were prepared in this study, the first being the control mixture (conventional mixture without adding recycled glass), while the second is the glasphalt mixture (glass replaces the natural aggregate at a different percentage).

\section{A. Effect of Glass Content on Marshall Properties}

The Marshall Test results of asphalt mixtures with various percentages of glass content and the specification requirements [16] are shown in Table 6. Properties of the glasphalt mixture were analysed and compared with the control mixture. 
TABLE VI

Properties of CONTRol AND Glasphalt MiXTURE With DifFERENT ReCyCled Glass Content

\begin{tabular}{|c|c|c|c|c|c|c|c|}
\hline \multirow{2}{*}{ Property } & \multicolumn{6}{|c|}{ Recycled Glass, \% } & \multirow{2}{*}{ Specification Requirements } \\
\hline & 0 & 5 & 10 & 15 & 20 & 25 & \\
\hline Stability, KN & 11.9 & 11.5 & 10.6 & 9.4 & 8.8 & 6.7 & $7 \mathrm{~min}$. \\
\hline Flow, mm & 3.93 & 3.9 & 3.71 & 3.62 & 3.6 & 3.64 & $2-4$ \\
\hline Bulk Density, gm/ $\mathrm{cm}^{3}$ & 2.324 & 2.313 & 2.301 & 2.294 & 2.288 & 2.273 & - \\
\hline V.T.M, \% & 4.11 & 3.92 & 3.84 & 3.56 & 3.40 & 2.93 & $3-5$ \\
\hline V.M.A, \% & 14.31 & 14.18 & 14.04 & 13.83 & 13.41 & 13.19 & 13 min. \\
\hline V.F.A, \% & 71.28 & 72.36 & 72.65 & 74.26 & 74.65 & 77.79 & - \\
\hline
\end{tabular}

The Marshall stability is the maximum load of specimen failure recorded with a constant rate of loading. The stability values will decline by adding a small amount of recycled glass to the mixes. The test results revealed that glasphalt mixes are finer than the control ones; therefore, rising finer material modifies the asphalt mixes by expending the asphalt binder that would otherwise cause a reduction in the stability values. Moreover, the smoothness of the glass surface and the flatness or elongation of large glass particles (size 4.75 $\mathrm{mm}$ ) will result in lower stability. Figure 9 illustrates the above theory. The stability value of the glasphalt mixture with $25 \%$ contents of glass replacement was below the minimum of the Iraqi specification requirement, which is 7 KN.

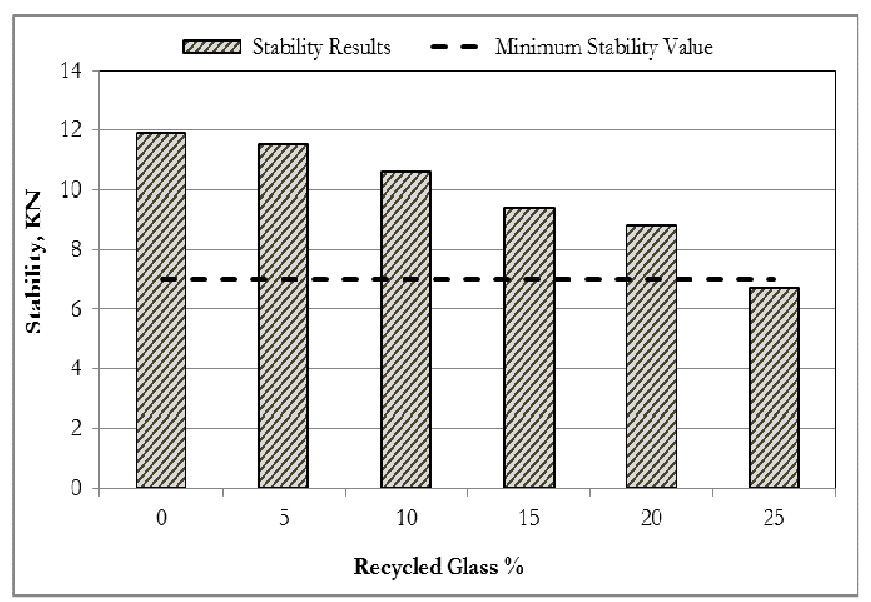

Fig. 9 Marshal Stability versus recycled glass content

Flow indicates the vertical deformation of the specimen. Mixtures with a high flow value will experience permanent deformation, whereas mixtures with a low flow value may be exposed to premature cracking resulting from mixture brittleness during pavement service life. The flow values of the glasphalt mixtures are between $2-4 \mathrm{~mm}$, and those that meet the specification requirement criteria are shown in Table 6 and plotted in Fig. 10.

As the replacement content of recycled glass increased from 5 to $25 \%$, the bulk unit weight values decreased because the glass had a lower bulk unit weight than the natural aggregate hence decreasing the bulk unit weight for glasphalt mixtures, as shown in Fig. 11.

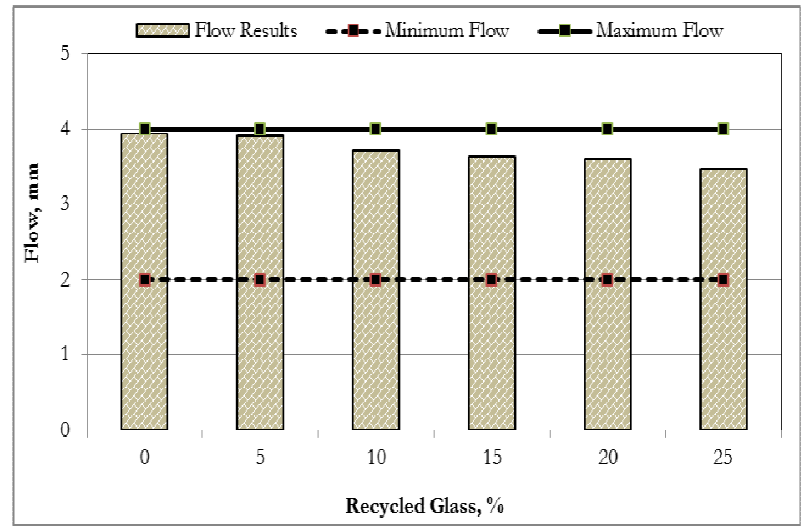

Fig. 10 Marshal flow versus recycled glass content

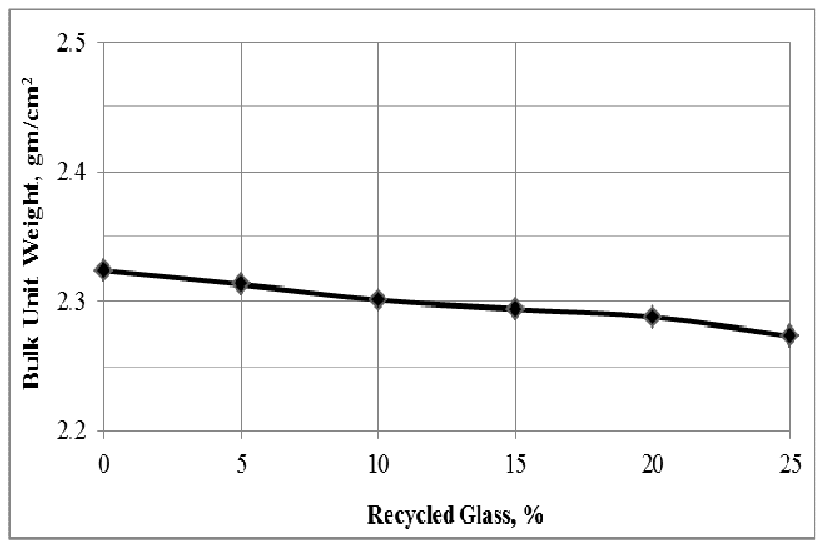

Fig. 11 Unit weight versus recycled glass content

When the inclusion of glass into asphalt mixtures increased, the voids in total mixture (V.T.M) gradually decreased and the voids in mineral aggregate (V.M.A) also dropped, as shown graphically in Fig.12 and Fig. 13. It is observed from the results that the control mix has the lower V.M.A and hence results in a lower effective asphalt content, so mixtures with no glass could be less durable than the glasphalt mixes prepared by adding higher glass contents of $20 \%$ and $25 \%$. Adding glass will help establish an adequate film thickness of the asphalt binder because asphalt is less absorbed into the glass. The air voids (V.T.M) of mixes decrease gradually as the glass replacement percentage increases in the mix. This drop in V.T.M in the mixes with glass content reflects the reduction in the internal pores of glass than the aggregate. The graph showing the voids filled with the asphalt (V.F.A) results is shown in Fig. 14. 


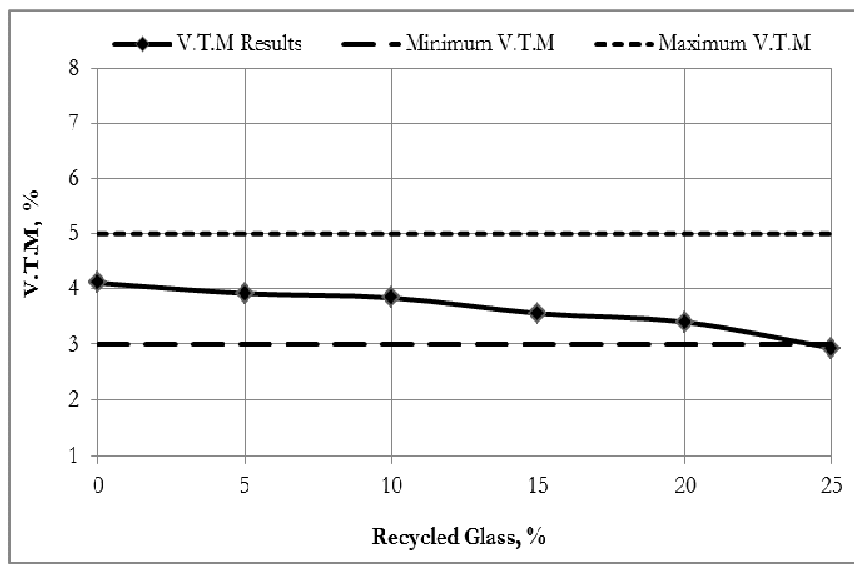

Fig. 12 Voids in total mixture (V.T.M) versus recycled glass content

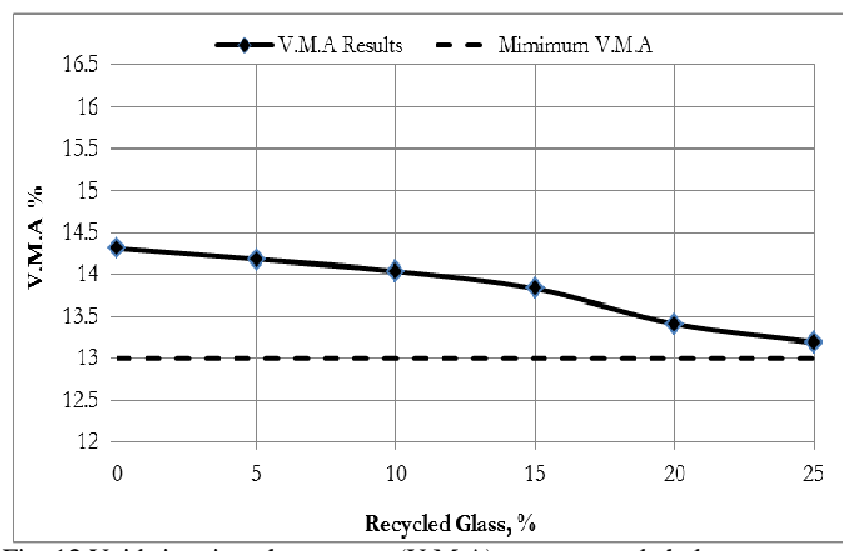

Fig. 13 Voids in mineral aggregate (V.M.A) versus recycled glass content

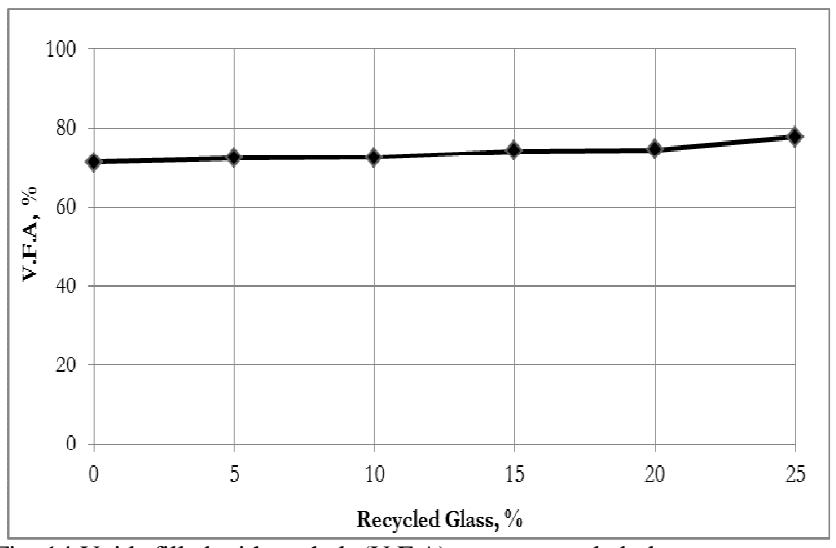

Fig. 14 Voids filled with asphalt (V.F.A) versus recycled glass content

\section{B. Effect of Glass Content on Indirect Tensile Strength}

Cohesive strength of asphalt mix is measured by indirect tensile test. A total of 18 samples were prepared to assess the effects of glass contents on the strength of the mix. The results of mix strength (ITS) property determined at 25,40 and $600 \mathrm{C}$ are illustrated in Fig. 15. The tensile strength of the glasphalt mix was comparable to a control mix for binder course with acceptable performance results. The tensile strength decreases significantly in mixtures that include higher contents of the waste glass material. According to Fig. 15 , increases in temperature result in decreases in the tensile strength of asphaltic samples.

Figure 16 displays the temperature susceptibility values. The temperature susceptibility result of the glasphalt mix was high when compared to the control mix, by $40 \%$. This might be because of the nature and properties of glass. Therefore, it appears that glasphalt mixture is more susceptible to temperature variation.

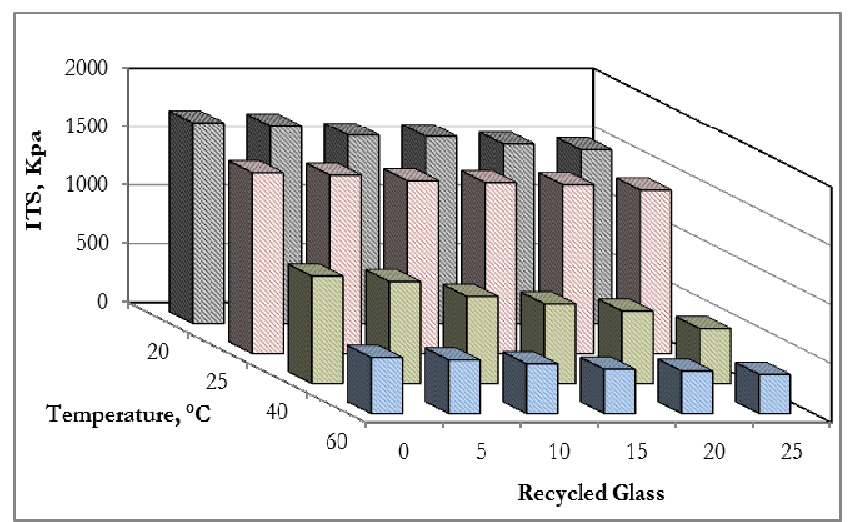

Fig. 15 Indirect tensile strength voids versus recycled glass content

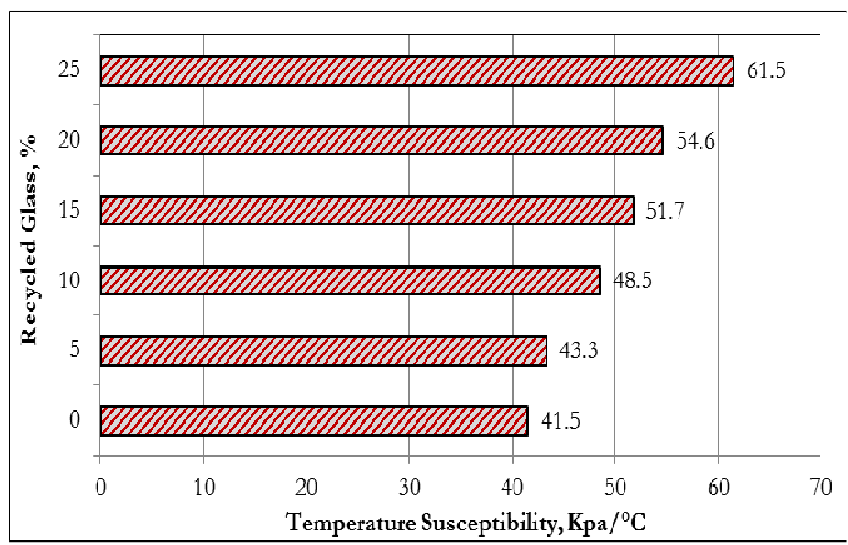

Fig. 16 Temperature susceptibility versus recycled glass content

\section{Effect of Glass Content on Moisture Damage}

Tensile strength ratio (TSR) results are presented in Fig. 17. The results indicate that the control mix produces the highest TSR as compared to glasphalt mixes; the control mixes offer better resistance to water damage impact than other mixes that are prepared with glass since their particles are less absorptive and bond poorly to asphalt binder, especially in the presence of water. Also, the larger particles of glass (size $4.75 \mathrm{~mm}$ ) and high content of glass have adverse influences on the resistance to water damage.

Very thin binder film could be seen by visual inspection on the surface of glass particles because glasphalt mixtures with no anti-stripping agents are more susceptible to stripping, as illustrated in Fig. 18(b). Evidently, water damage resistance of glasphalt mixtures is improved when $2 \%$ of hydrated lime is added to the mixture, which also effectively eliminates visible stripping by establishing an adequate adhesion bond between asphalt and the glass surface, as shown in Fig. 18(a). It has been established that hydrated lime additive will raise the TSR values, as presented in Fig. 17.

All glasphalt mixtures with hydrated lime addition produced adequate stripping resistance, except the mixture containing $25 \%$ glass content, because TSR is less than the minimum criterion of $80 \%$. 


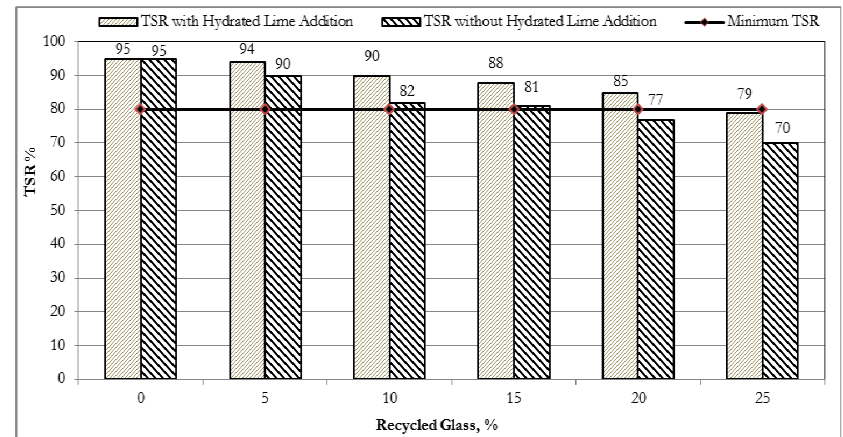

Fig. 17 Tensile strength ratio versus recycled glass content
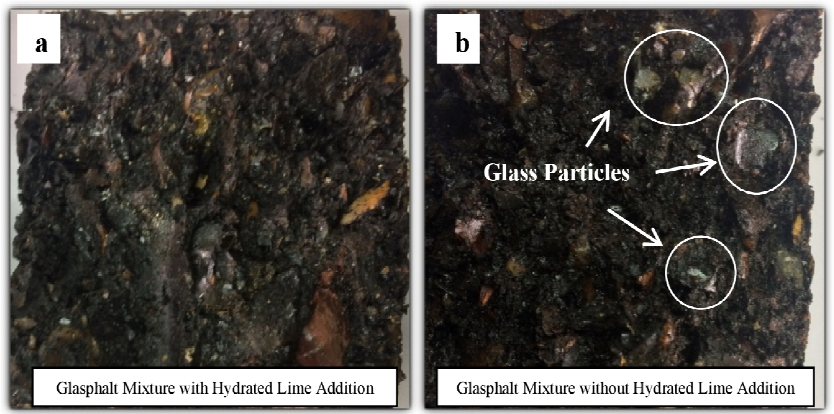

Fig. 18 The internal state of stripping for glasphalt mixture after moisture damage test

\section{Effect of Glass Content on Punching Shear Strength}

The DPS test indicates the stripping behavior between aggregate and asphalt binder. The stripping performance was the concern of the work because the smooth surface of glass particles in the glasphalt mixture affects adhesion mechanism. Figure 19 presents punching shear strength results for glasphalt and control mixtures. The results were unexpected and showed that control mixtures had punching strength values lower than glasphalt mixtures except for samples with a glass content of $25 \%$. This may be because hydrated lime was added as an anti-stripping agent to glasphalt mixtures which is effective in eliminating stripping action. Glasphalt mixture with $5 \%$ of glass content had the highest punching strength value.

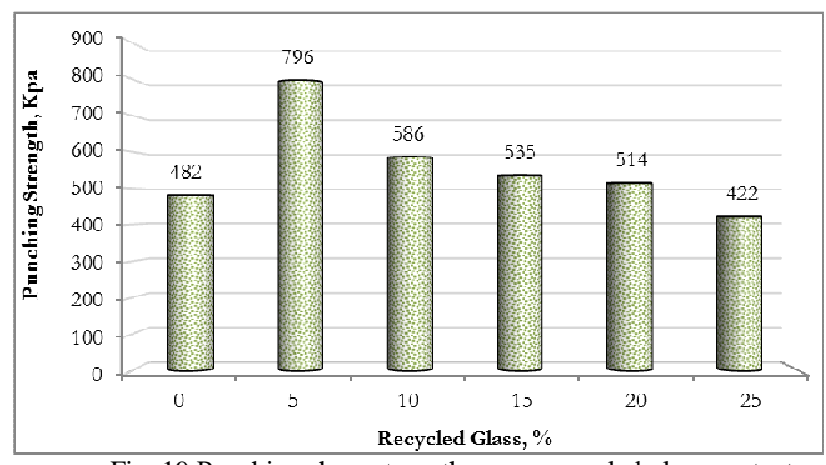

Fig. 19 Punching shear strength versus recycled glass content

\section{E. Effect of Glass Content on Permanent Deformation}

Based on repeated load data, the plastic coefficients, intercept (a) and slope (b), can be obtained by plotted the $\log -\log$ relationship between the plastic microstrain $(\varepsilon)$ and a number of repetition $(\mathrm{N})$ as shown in Fig. 20, then computed parameters (Alpha and $\mathrm{Mu}$ ) which is used as a measure of asphalt mixture resistance to permanent deformation, as presented in Table 7.

Glasphalt mixture exhibits good resistance to permanent deformation in comparison with conventional asphalt mixture. This is based on the finding in Fig. 20 and Table 7 that Alpha $(\alpha)$ value for glasphalt mixture was little more than that of the conventional mixture while $\mathrm{Mu}(\mu)$ value decreased. It can see that the addition of crushed glass up to $10 \%$ leads to higher resistance against permanent deformation because of the higher internal friction of crushed glass as a result of the increased angularity and this will, in turn, increase the interlock between coarse particles of crushed glass and aggregate. Furthermore, Glasphalt sample with $25 \%$ of crushed glass posed deterioration to deformation resistance more than the conventional sample.
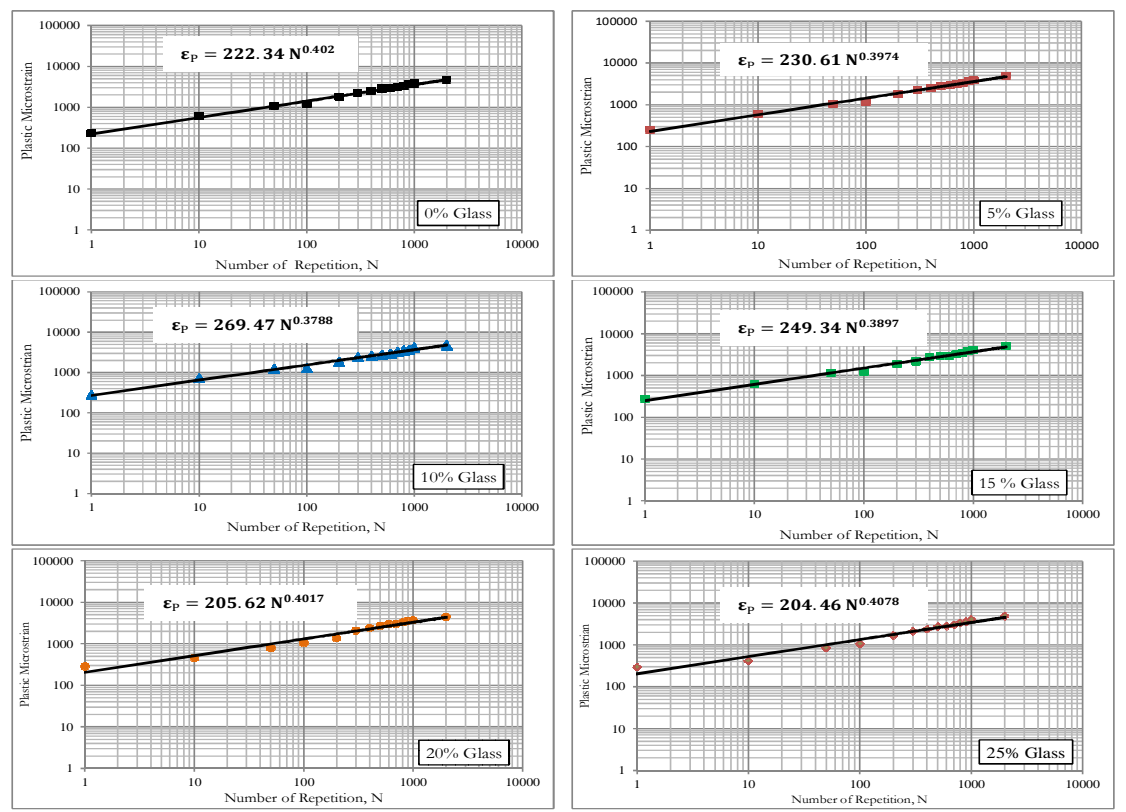

Fig. 20 Plastic microstrain versus number of repetition 
TABLE VII

PERMANENT DEFORMATION PARAMETRS

\begin{tabular}{|c|c|c|c|c|c|c|}
\hline \multirow{2}{*}{ Permanent Deformation Parameters } & \multicolumn{7}{|c|}{ Glass Content, \% } \\
\cline { 2 - 7 } & 0 & 5 & 10 & 15 & 20 & 25 \\
\hline$\alpha$ & 0.5980 & 0.6026 & 0.6212 & 0.6103 & 0.5983 & 0.5922 \\
\hline$\mu$ & 0.630 & 0.615 & 0.589 & 0.597 & 0.632 & 0.650 \\
\hline
\end{tabular}

\section{CONCLUSIONS}

Based on the obtained results, the following conclusions were made: There is a potential to replace natural aggregate of asphalt mixture with crushed glass. This is based on the finding that the attributes of glasphalt mixture, such as Marshall Stability, flow, moisture damage resistance, and permanent deformation could achieve the standards of the asphalt mixture design for binder course. Based on mixture performance indicators, recycled glass can be used in asphalt concrete mixture for a binder course with a maximum size of $4.75 \mathrm{~mm}$ and substitution content up to $20 \%$ by weight of total aggregate. Efficient performance of binder layers can be accomplished by adding waste glass with $10 \%$ content to the mix. Hydrated lime in glasphalt mixtures is a useful treatment to improve the moisture damage resistance. The permanent deformation of glasphalt mixture increased when crushed glass content increased more than $20 \%$. Using glasphalt mixture will save raw materials and reduce solid waste material while improving mixture performance.

\section{REFERENCES}

[1] G. L. Nancey, and M. P. Lynn, "Construction \& demolition debris recycling for environmental protection and economic development," Univ. of Louisville, Southeast Regional Environmental Finance Center, EPA Region 4, Practice Guide no. 7, 2004

[2] A. A. Rola, R. M. Abdul Hamid, A. S. Mazhar, S. K. Imad, H. A. Safaa, A. Qassim, and A. Suad, "Economic returns from recycling (re-use) solid waste - a statistical study," Association of Arab Universities Journal of Engineering Sciences, Vol. 21, no. 1, pp. 3346, 2015.

[3] I. Barišić, M. Zagvozda, and S. Dimter, "Usage of alternative environmentally acceptable materials-experience from Eastern Croatia," in 2nd International Conference on Innovative Materials, Structures-and Technologies 96, 2015, paper 012082, p. 1.

[4] P. T. Nash, P. W. Jayawickrama, R. W. Tock, S. P. Senadheera, K Viswanathan, and B. Woolverton, "Use of glass cullet in roadway construction," Texas Department of Transportation, Rep. 0-1331-2, 1995.

[5] "Markets for recovered glass," United States Environmental Protection Agency, Policy, Planning and Evaluation, 1992.

[6] W. Shaopeng, Y. Wenfeng, and X. Yongjie, "Preparation and properties of glass-asphalt concrete," Key Laboratory for Silicate Materials Science and Engineering of Ministry of Education, 2004 paper 430070 .
[7] P. S. Kandahl, "Waste materials in hot mix asphalt- an overview,' National Center for Asphalt Technology," ASTM meeting in Miami, Rep. 92-06, 1992.

[8] L. S. David, C. J. Newton, and W. A. Keith, "Used of recycled materials in highway construction," Washington state department of transportation, Rep. WA-RD 252.1, 1992.

[9] W. R. Malisch, D. E. Day, B. G. Vixson, and K. O. Anderson, "Use of domestic waste glass as aggregate in bituminous concrete," Highway Research, Washington, Rep. 307, 1970.

[10] W. Chesner, "Waste glass and sewage sludge ash use in asphalt pavement," Utilization of Waste Materials in Civil Engineering Construction, American Society of Civil Engineering, 1992, P.45.

[11] R. John, "Reuse/recycling of glass cullet for non-container uses," Dane County Department of Public Works, July, 2003.

[12] T. A. Zaydoun, S. K. Taisir, B. B. Musa and A. Raed, "Effect of waste glass on properties of asphalt concrete mixtures," Jordan Journal of Civil Engineering, Vol. 11, no. 1, pp. 117-131, 2017.

[13] G. H. Shafabakhsh, and Y. Sajed, "Investigation of dynamic behavior of hot mix asphalt containing waste materials; case study: glass cullet," Case Studies in Construction Materials, Vol. 1, pp. 96103, 2014.

[14] J. A. Boateng, and T. George, "Laboratory Investigation of the performance properties of hot mix asphalt containing waste glass," Proceedings of the 35th Southern African Transport Conference, SATC, 2016, p. 49.

[15] G. Arnold, S. Werkemeister, and D. Alabaster, "The effect of adding recycled glass on the performance of basecourse aggregate," NZ Transport Agency, New Zealand, Rep. 351, 2008.

[16] General Specification for Roads and Bridges (SCRB), Section R/9, Hot-Mix Asphalt Concrete Pavement, Revised Edition, State Corporation of Roads and Bridges, Ministry of Housing and Construction, Republic of Iraq, 2003.

[17] A. M. Husham, "Evaluation of suitable temperature susceptibility index for local paving asphalts," M. Eng. thesis, Civil Engineering Department, University of Baghdad, Baghdad,Iraq, 1999.

[18] R. A. Jimenez, "Testing for debonding of asphalt from aggregates," National Highway Research Council, Transportation Research Record 515, TRB, Washington, 1974.

[19] O. T. Farouki and J. Rolt, "Feasibility of using sand/sulphur/bitumen mixes in highway pavement construction," s.1. : The Chartered Institution of Highway \& Transportation, 1985.

[20] A. H. Albayati, "Permanent deformation prediction of asphalt concrete under repeated loading," Ph.D. Eng. thesis, Civil Engineering Department, University of Baghdad, Baghdad, Iraq, 2006.

[21] Y. H. Huang, "Pavement Analysis and Design," 2nd ed., Upper Saddle River - New Jersey, Pearson Prentice Hall, 2004.

[22] C. Monismith, N. Ogawa and C. Freeme, "Permanent deformation characteristics of subgrade soils due to repeated loadings," 54th Annual Meeting of the Transportation Research Board, Washington, TRR, 1975 , paper 00126815 , p. 1.

[23] R. Barksdale, "Laboratory evaluation of rutting in base course materials," Third International Conference on the Structural Design of Asphalt Pavements, paper 00261964 , 1972, p. 161. 